
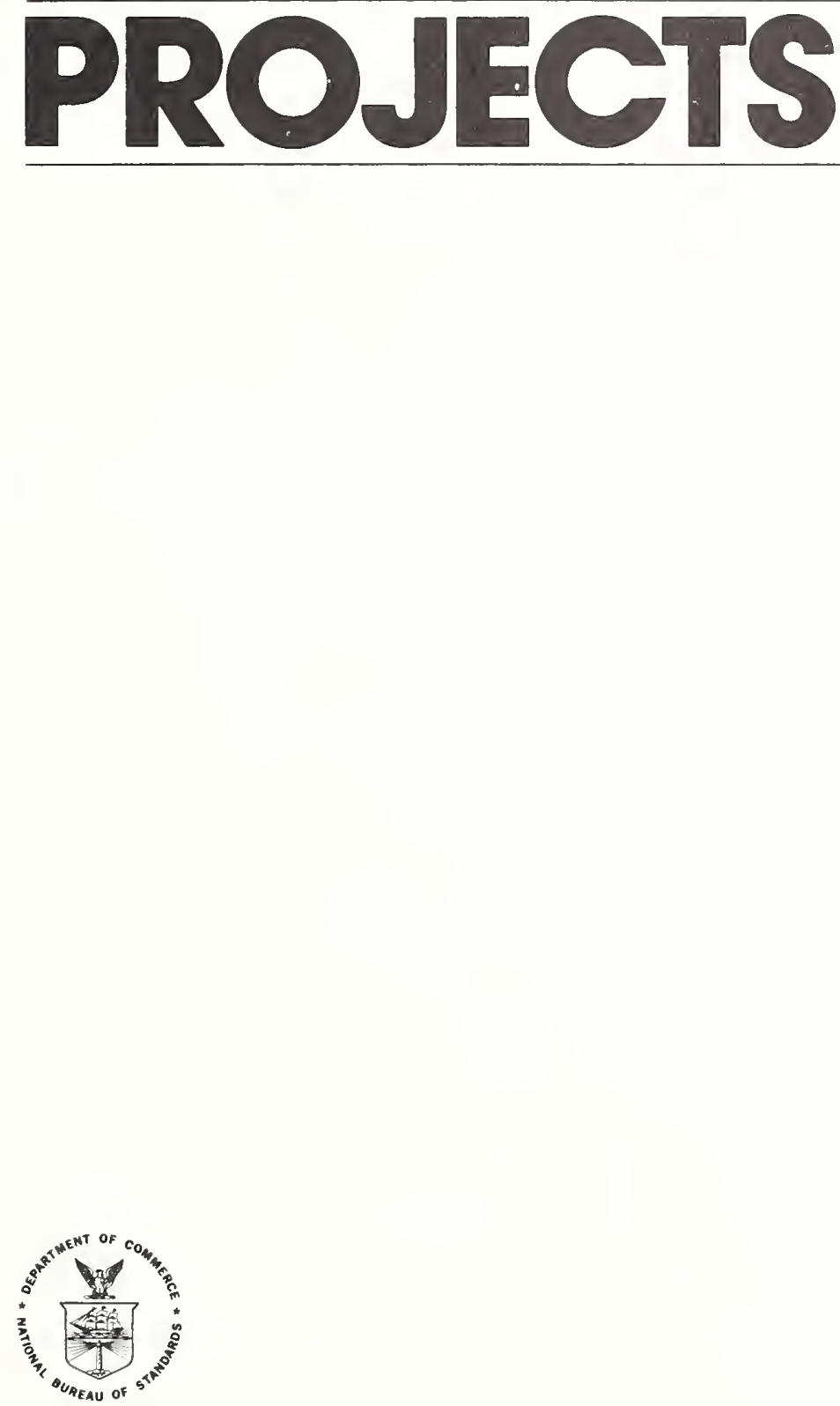

U.S. DEPARTMENT OF COMMERCE / National Bureau of Standards

National Engineering Laboratory / Center for Building Technology 
0

0

두 


\section{TECHNIQUES FOR ECONOMIC EVALUATION OF BUILDINGS}

Harold E. Marshall

Applied Economics Program

Building Economics and

Regulatory Technology Division

301-921-3701

Sponsor - National Bureau of Standards
The objective of this project is to develop and refine the theories and methods of benefit-cost analysis, risk-benefit analysis, and life-cycle costing for applications to new technologies and policies related to the environment, energy conservation, and particularly buildings and construction.

The approach is as follows: (1) to conduct a literature search on available evaluating methods and statistical data, both in the U.S. and abroad; (2) to examine non-building applications of evaluation techniques to determine their applicability to building problems; (3) to examine alternative methods for evaluating losses of life and personal injuries; (4) to examine techniques for evaluating alternative building designs for preventing losses from fire and other disasters, and for reducing the consumption of energy; and (5) to examine cost-sharing rules as they impact on construction design and scale.

Accomplishments for this project include refined benefitcost, risk-benefit, and life-cycle cost methods for evaluating alternative building technologies; participation in seminars, training, and research relating to application of these methods; Federal workshops on building economics; publication of numerous articles in professional and laymen oriented journals; and completion of many Bureau publications covering energy conservation, rehabilitation of housing, and environmental enhancement through wastewater and solid waste control.

In Executive Order 12003, President Carter required that life-cycle costing be used by all Federal agencies in reducing their energy consumption in existing and new buildings by 20 and 45 percent, respectively, by the year 1985 . The objective of this project is to provide technical support on life-cycle costing to the Department of Energy (DoE). The first step in the effort was to survey the life-cycle costing procedures now in use by government agencies. The second step was to develop a guide to uniform life-cycle costing practices to be used by all Federal agencies. The completed guide in draft, entitled "Life-Cycle Costing Guide for Selecting Energy Conservation Projects for Public Buildings" is now being considered for adoption as part of DoE's overall guidelines for the Federal Energy Management Program. The guide describes alternative life-cycle costing approaches for determining the cost effectiveness of energy conservation projects, and recommends a criterion for ranking candidate projects in order of investment priority. It outlines approaches for treating both simple and complex investment problems, and includes sample worksheets, supporting tables, rules for making basic assumptions, and a glossary of terms.

As a part of a multi-disciplinary project aimed at improving the performance of windows in buildings, the AEP has investigated the comparative cost effectiveness of selected alternative window designs, sizes, accessories, and modes of use. A life-cycle costing model and companion computer program have been developed for use by the building community to determine the net impact of alternative window systems on life-cycle capital, maintenance, and energy costs of residential and commercial buildings. To illustrate the use of the method, as well as to develop pre- 


\section{ECONOMIC ANALYSIS OF LEAD- PAINT ABATEMENT TECHNIQUES}

\author{
Robert Chapman \\ Applied Economics Program \\ Building Economics and \\ Regulatory Technology Division \\ 301-921-2278
}

Sponsor - Department of Housing and Urban Development liminary guidelines for window selection and use, the model has been applied in 18 case studies--nine for a residence and nine for a commercial office building--in nine different geographical locations of the U.S.

The net impacts on life-cycle costs are assessed of changing window size; using double or triple glazing instead of single glazing; changing the directional orientation of the window; equipping the window with Venetian blinds and insulating shutters; and using the daylight available from windows to reduce the use of electric lighting.

Public and private concern about the potential for lead poisoning in children due to the ingestion of lead-based paint chips has resulted in a Federally sponsored program to develop technologies by which the lead-based paint hazard may be eliminated from the nation's housing. Through the Experimental Hazard Elimination Program (EHEP), lead-based paint abatement techniques were tested in field deleading operations conducted in Boston, Massachusetts. The major focus of EHEP was on the collection of data on the direct costs of labor, materials and special equipment associated with these abatement techniques. Data were also collected on contractors' bids so that markup ratios could be calculated.

Two reports based on the findings of EHEP are to be published. The first report, Guidelines for Cost-Effective Lead Paint Abatement, provides an overview of the statistical analysis of the EHEP cost data by abatement technique and building component (i.e., walls, doors and frames, windows and frames, and miscellaneous trim).

The second report, Lead Paint Abatement Costs: Some Technical and Theoretical Considerations, focuses on the design, implementation, and analysis of EHEP and the cost information it produced. These reports are extensions of previous research published in NBS Technical Note 922, Economic Analysis of Experimental Lead Paint Abatement Methods: Phase I, and in the Journal of Housing article "Lead Paint Poisoning: A Closer Look at the Costs."

The purpose of this project is to develop a comprehensive and authoritative reference of basic, useful information in the field of solar energy economics. It is important to develop comprehensive reference documents to guide the economic analysis of solar energy systems during this critical period of system research and market development which will have long-run, far-reaching impact on the success of solar energy as a practicable energy source. This project aggregates previous NBS work in this field and expands it in key areas in order to provide a comprehensive document which can be used to respond to the many requests received by NBS from government agencies, industry, researchers, consumers, and other members of the building community. 
SOLAR COMMERCIAL HANDBOOK

Rosalie T. Ruegg

Applied Economics Program

Building Economics and

Regulatory Technology Division

301-921-2330

Sponsor - Department of Energy
The purpose of this project is to provide the building community with information on the economic feasibility of solar energy systems for new and existing commercial and institutional office buildings and retail stores. Several types of buildings, solar energy systems, and mechanical systems will be selected for study; representative geographical locations will be selected; an attempt will be made to develop an improved optimization model; an analysis will be made of thermal loads and system performance; cost-effectiveness measures will be developed based on optimized system design; and an NBS technical report and an easy-touse handbook (Special NBS Publication) will be prepared.

This project will help Federal and State legislators

\section{INCENTIVE POLICIES FOR SOLAR ENERGY SYSTEMS}

Rosalie T. Ruegs

Applied Economics Program

Building Economics and

Regulatory Technology Division

301-921-2330

Sponsor - National Bureau of Standards

formulate effective policies for encouraging the use of solar energy systems in building. It does this by comparing the cost savings of alternative incentive policies. A life-cycle cost model and a counterpart computer program have been developed to analyze seven different kinds of incentive policies now being considered for adoption by many State legislatures and by the U.S. Congress. These are (1) direct grants, (2) income tax credits, (3) property tax exemptions, (4) sales tax exemptions, (5) loan interest subsidies, (6) income tax deductions for system depreciation, and (7) changes in the tax treatment of fuel purchases.

The model has been applied in six case examples for each of the seven selected incentives, demonstrating that some of the incentive policies now being enacted will not be worth the administrative costs required to implement them, and that the effectiveness of a given policy will vary considerably by region, by fuel price, and for residential solar systems as compared with those used on commercial buildings. A report which describes the evaluation model, the computer program to exercise the model, and the case examples has been prepared.

In recent years construction costs have risen faster than the general cost of living, and many persons contend that the construction industry is technologically backward and inefficient. Some observers believe that an important constraint on the construction industry is restrictive building codes which promote inefficiency and substantially increase costs, while other experts believe that this constraint is small. Differing opinions concerning the impact of building codes exist in part due to the lack of appropriate information. This study develops an economic framework to help identify the impact of building codes on construction costs, and upon the distribution of income between buyers, builders, building material producers, and construction workers.

To increase information for decision makers, the study provides a standardized method of analyzing the economic impact of specific building code changes. Building officials seek to improve public health, safety, and welfare through building codes.

This study is designed to be especially useful to building officials in choosing between two code alternatives, or between the choice of enacting or not enacting a code change. It concludes with a case study of one particular code change, the requirement for ground fault circuit interrupters, to illustrate the use of this method of analysis. 


\section{ECONOMICS IN BUILDING}

\section{STANDARDS}

Stephen R. Petersen

Applied Economics Program

Building Economics and

Regulatory Technology Division

301-921-3126

Sponsors - Department of Housing and Urban

Development and Department of Energy

\section{ECONOMICS IN NEW HOUSING DESIGN}

Stephen R. Petersen

Applied Economics Program

Building Economics and

Regulatory Technology Dioision

301-921-3126

Sponsors - Department of Housing and Urban Development arid Department of Energy

\section{RETROFITTING EXISTING HOUSING FOR ENERGY CONSERVATION: AN ECONOMIC ANALYSIS}

Stephen R. Petersen

Applied Economics Program

Building Economics and

Regulatory Technology Dioision

301-921-3701

Sponsor - Federal Energy Administration
This project provided analytical support of an economic nature to the NBS Building Energy Performance Standards program. The economic impacts of alternative approaches to the development of standards for energy conservation in new buildings were evaluated. The potential role of economic analysis as an integral part of standards development was explored. Reports of research findings from these projects recommend that economic considerations be incorporated into the actual standards development process.

This project was undertaken to provide data useful in demonstrating how economic analysis can be used in the design process for new housing with respect to energy conservation. A variety of design modifications to the building envelope was considered, including structural modifications that are impractical in retrofit situations. The NBS Load Determination (NBSLD) program was used to estimate the effect of these modifications on annual heating and cooling requirements. Cost data for the design modifications considered were provided by the NAHB Research Foundation. Optimal design configurations for a wide range of climates and energy costs were established. The data will be published in the NBS Building Science Series.

This project examined the economic aspects of energy conservation techniques suitable for retrofitting into existing housing. Insulation, storm windows and doors, and weather stripping were considered. The objective is to determine that combination of techniques which will minimize life-cycle (20 year) costs for heating and air conditioning, subject to specific assumptions regarding comfort, climatic conditions, fuel costs, and retrofitting costs. Insulation thickness in attics and floors and around duct work is varied over a wide range. Storm window and storm door applications are considered for a variety of existing conditions. Using marginal analysis, we find that each technique should be utilized up to the point where present value life-cycle savings generated by the last increment will just equal the cost of that last increment. Thermal engineering data are combined with economic analysis in a computer assisted model which estimates such optimal combinations for a wide range of climatic conditions and fuel costs. These combinations include levels of application considerably higher than what has been previously recognized as "economical." Results of the research are published in Retrofitting Existing Housing For Energy Conseroation.

The Consumer booklet makes information available to owners of existing housing regarding the most economical use of insulation, storm windows and doors, and weather stripping. Technical data developed in an earlier NBS Report, Retrofitting Existing Housing for Energy Conservation, are presented in a format which can be easily understood and utilized by homeowners. An index system is presented which relates both energy prices and climate factors to economically optimal levels of energy conservation investments. The benefits of a balanced approach to energy 


\section{ANALYTICAL SUPPORT TO DoE MORTGAGE DEMONSTRATION PROGRAM}

Stephen R. Petersen

Applied Economics Program

Building Economics and

Regulatory Technology Division

301-921-3126

Sponsor - Department of Energy

conservation in the home are discussed. Some basic information on retrofitting procedures and problems is presented.

The Department of Energy has initiated a demonstration program to encourage mortgage lenders to include certain energy conservation improvements in the size of the loan granted at the time of resale. This project was undertaken at the request of DoE to evaluate and recommend potential energy conservation features that could be included in such a program on the basis of positive net benefits over the life of the mortgage. Eight conservation features were examined for nine cities and four heating systems for a typical single-family, wood-frame dwelling. Conservation investments that were generally cost effective are R-19 attic insulation, storm windows (over single glazing), and $\mathrm{R}-11$ floor insulation.

A number of potential design improvements in domestic

\section{BENEFIT-COST ANALYSIS OF IMPROVED EFFICIENCY IN DOMESTIC HVAC EQUIPMENT}

Stephen R. Petersen

Applied Economics Program

Building Economics and

Regulatory Technology Division

301-921-3126

Sponsor - Department of Energy

\section{ECONOMIC GUIDELINES FOR INSULATING MASSIVE WALLS IN RESIDENTIAL CONSTRUCTION}

\author{
Stephen R. Petersen \\ Applied Economics Program \\ Building Economics and \\ Regulatory Technology Division \\ 301-921-3126 \\ Sponsor - Department of Energy
}

\section{EFFECTS OF RESOURCE IMPACT FACTORS}

Stephen F. Weber

Applied Economics Program

Building Economics and

Regulatory Technology Division

301-921-2308

Sponsors - Federal Energy Administration and

Energy Research E Development Administration heating and central air conditioning equipment is being evaluated to determine benefits and costs. Computer models developed at NBS and by a major equipment manufacturer are being used to calculate performance in a range of design and usage variations. Cost data for the design changes are being collected. A technical report with guidelines for selecting HVAC equipment with the lowest lifecycle cost in different climates and for different energy costs will be published

An investigation is being conducted on the costs and benefits of insulating masonry and other massive walls to various levels of thermal resistance. Because the techniques of insulating such walls and the potential energy savings may be significantly different than for wood frame walls, separate guidelines must be developed. Dynamic computer analysis of the thermal performance of various types of massive walls with a range of insulating levels is being undertaken. Results will provide guidelines for different climates, different energy costs, and different methods of insulating these walls in new residential construction.

This study addressed the question of the proper price for energy to be used in the development of optimal (i.e., cost-effective) energy conservation performance standards for buildings. It was found that the appropriate price for energy is its social value, which should be determined through the development and application of Resource Impact Factors (RIF's). Some guidelines were provided for the formulation and development of RIF's. A life-cycle cost minimization model for determining the optimal conservation standard was employed to show how the use of RIF's would generally lower the maximum allowable energy consumption specified in the standard. Indeed, it was found that the higher the RIF value, the lower the energy consumption allowed by the standard, although this effect steadily diminishes as the RIF value increases.

For example, a RIF value of 2.0 could cause additional 


\section{SOLID WASTE COST ALLOCATION METHODS}

Stephen F. Weber

Applied Economics Program

Building Economics, and

Regulatory Technology Division

301-921-2308

Sponsor - Environmental Protection Agency energy savings of more than $29 \%$ of the annual energy consumption under a standard not using RIF's. The extra energy savings resulting from RIF's were also shown to increase as the severity of the climate increases. The use of RIF's to develop energy conservation standards would lead to additional energy savings which are over $41 \%$ greater when applied to a region with twice the energy load as another region. When the assumptions of the cost model were modified, similar relationships were observed between the extra energy savings from using RIF's on the one hand, and the size of the RIF value and the climate severity, on the other hand. Finally, a geometric measure was derived for the net gain in economic efficiency that would result from using RIF's in developing optimal energy conservation standards for new buildings.

Currently, the municipal taxes or private fees paid by an individual household or building occupant for solid waste management services bear little relation to the actual cost of disposing of the wastes produced by that household or occupant. Generally, a fixed monthly fee or a portion of local property taxes is paid for the disposal service, regardless of either the amount of waste generated by a particular household or the actual costs imposed on the waste management system by that household. Thus, there is no incentive for those who generate solid waste even to consider the disposal costs associated with the products they use, let alone to modify their consumption patterns accordingly. A product charge has been proposed as one method of internalizing the disposal costs of products entering the solid waste stream.

The principal objective of this study is to develop an appropriate method for allocating the costs of collection, transport, and disposal among the separable components of the waste stream. This method could serve as the basis for determining a cost-based product charge to be levied on specific manufactured goods destined to enter the waste stream. While most data on solid waste management systems is reported in terms of weight, it is apparent that at least some disposal costs depend on volume. Thus, the two major issues which this method will address are: (1) how to convert weight data to volume data by measuring densities; and (2) how to include both weight and volume in a cost function in a manner which adequately reflects each parameter's relative contributions to total disposal costs.

In order to develop volume data for the cost allocation, density measurements will be made at three points in the waste disposal process: the refuse container, the truck at the disposal tip site, and the in-place refuse at the landfill. A cost allocation model will be developed to assign waste management costs at each stage of disposal on the basis of both weight and volume. The weight-based and volumebased costs will be converted to a per unit basis of the manufactured product so that all disposal costs of a particular component can be added together to comprise single per unit charge at the production stage. Individual reports will be published on: (1) The Cost Allocation Methodology; and (2) The Density Determination Method.

If legislation on a product charge is enacted, the cost allocation and density measurement methods being developed will be useful to EPA in implementing the charge. 
ANALYSIS OF COST-SHARING PROGRAMS FOR POLLUTION ABATEMENT OF MUNICIPAL WASTEWATER

Harold E. Marshall

Applied Economics Program

Building Economics and

Regulatory Technology Division

301-921-3701

Sponsor - Enoironmental Protection Agency

\section{ECONOMICS OF RECYCLING BUILDINGS}

Stephen F. Weber

Applied Economics Program

Building Economics and

Regulatory Technology Division

301-921-2308

Sponsor - National Bureau of Standards
This study evaluates existing cost-sharing programs for wastewater pollution abatement as described in the Federal Water Pollution Control Act Amendments of 1972, describes alternative cost-sharing programs that provide improvements in terms of national efficiency and equity criteria as defined in the study, and suggests related areas for further research. Emphasis is on how Federal cost sharing biases communities in favor of certain kinds of techniques. The approach is to describe the current costsharing programs for both plant and nonplant techniques; to examine cost-sharing, legal, and other institutional biases against certain techniques; to analyze efficiency and equity effects of alternative cost-sharing programs; and to describe the incentive effects of cost-sharing on nonfederal interests with respect to their choices among abatement techniques. Findings of the study are that more efficient abatement will result if the same percentage cost share applies to all plant and nonplant tecniques of abatement; the same percentage also applies to all categories of cost (e.g., capital, land, operation and maintenance) for a given technique; the same percentage applies to large and small communities; institutional constraints on the selection of non-plant techniques are removed; and if the program provides for Federal cost sharing of every abatement technique that is technically viable.

The Tax Reform Act (TRA) of 1976 contains a number of provisions which affect the financial position of the owner of an historic building who faces a decision whether to rehabilitate the structure or to demolish it and construct a new one on the site. The purpose of this research is to provide such owners or potential investors in historic properties with information on the relative economic merits of these alternatives both before and after the enactment of the TRA. The analysis was conducted from a life-cycle cost point of view so that all of the financial impacts of the tax provisions occurring over the lifetime of the structure could be taken into account. Thus, full consideration was given to the tax benefits of depreciation (or amortization) deductions occurring each year, as well as to the tax liabilities arising from capital gains and recapture which occur at the disposition of the property. The life-cycle cost model calculated the sum of the following items: (1) rehabilitation costs (or demolition and construction costs); (2) minus the present value of the tax reductions due to annual depreciation write-offs; (3) plus the present value of the capital gains taxes and recapture taxes due when the property is sold; and (4) minus the present value of the proceeds from the sale. These calculations were made for the rehabilitation and the redevelopment options before and after TRA. For the case of rehabilitation after TRA, separate calculations were made for each of three alternative situations: (1) accelerated depreciation for substantial rehabilitation; (2) rapid amortization with full recapture; and (3) rapid amortization with partial recapture. Sensitivity analysis was conducted with respect to several key parameters: (1) the holding period; (2) the discount rate; and (3) demolition costs.

The results indicated that the TRA has significantly affected the economic trade-off between rehabilitation and redevelopment. Before the TRA, rehabilitation was 
NATURAL DISASTERS: SOME EMPIRICAL AND ECONOMIC CONSIDERATIONS

\author{
G. Thomas Sav \\ Applied Economics Program \\ Building Economics and \\ Regulatory Technology Division \\ 301-921-3126 \\ Sponsor - National Bureau of Standards
}

between $4 \%$ and $9 \%$ more costly than redevelopment, whereas after TRA, rehabilitation was between 13\% and $29 \%$ less costly than redevelopment, when the rapid amortization provision was used.

This study examines the extent of some of the losses resulting from natural disasters. An estimate of these losses is necessary in order to determine the potential benefits that might be realized from mitigating the negative economic impacts from natural disasters. Absolute and relative losses resulting from hurricanes, floods, earthquakes, and tornadoes are examined. These data will help individuals, communities, and the Federal government make better decisions as to how and what extent protection against disasters should be provided. The application of benefit-cost analysis for choosing the optimal level of protection against disasters is also discussed. Recommendations are made for further research in determining the economic feasibility of various techniques designed to mitigate the losses from disasters.

This project is part of an interdisciplinary project which has as its objective the development of performance requirements which will form the basis for modifications to the HUD Mobile Home Construction and Safety Standard. The approach will be to first identify the relevant economic costs and benefits associated with the egress provisions of the existing HUD Standard. In conjunction with the interdisciplinary project team, proposed changes to the existing egress provisions will be selected. Life-cycle benefit cost analysis will be performed during the standards development process to help identify early those modifications to the egress standards which are potentially most cost effective.

Public and government concern about the progressive collapse of buildings caused by abnormal loading has resulted in the development of draft standards to provide protection against progressive collapse. From society's viewpoint, standards for protection against progressive collapse should result in a level of protection which is more efficient (i.e., the net social benefits from protection should increase). An economic model utilizing the principles of benefit-cost analysis is developed which establishes a methodology for determining the efficiency of various levels of protection against progressive collapse. An application of the model to a partial evaluation of a specific standard demonstrates some of the capabilities of the model. Recommendations are made for a complete evaluation of this standard and for the further refinement of the model. 


\section{AN ECONOMIC ANALYSIS OF RESIDENTIAL ABANDONMENT AND REHABILITATION}

Robert Chapman

Applied Economics Program

Building Economics and

Regulatory Technology Division

301-921-2278

Sponsor - National Bureau of Standards

\section{THE ECONOMICS OF HOUSING NEEDS: A METHODOLOGICAL GUIDE}

Robert Chapman

Applied Economics Program

Building Economics and

Regulatory Technology Division

301-921-2278

Sponsor - Agency for International Development
This study analyzes the underlying economic determinants of individual behavior regarding maintenance and rehabilitation at the dwelling unit level. The individual housing investment decisions are then connected to a model of the aggregate housing market to facilitate understanding of the process of abandonment and rehabilitation. One conclusion is that while technological change in new housing production will accelerate the rate of filtering down, it may also exacerbate blight in the central cities. This study also examines the impacts of property taxation, low-growth policies, changes in income, and changes in maintenance costs on the housing investment process.

This study develops a procedure for estimating the level of housing needs in a given region and for projecting needs estimates in the future. The study approaches housing need estimation as an endeavor in estimating the redistributive impacts of housing programs which are designed to upgrade housing conditions in the slum and squatter sectors of the housing market. The concept of "housing needs" is analyzed by using a stock flow model of the housing market. One spinoff finding is that the implementation costs of the housing subsidy program may make it an inefficient alternative for redistributing income.

This report provides preliminary information to the Department of Housing and Urban Development about its Modular Integrated Utility System (HUD-MIUS) program. Specifically, the study focuses on the economic decisionmaking process for implementation of a MIUS by utility companies, developers, or a combination of these two groups. Conclusions are that MIUS is most likely to be implemented by a government body rather than a private developer under the existing institutional structure.

This project developed a general model of equipment performance as a function of maintenance that permits quantification of the optimal level of maintenance in terms of performance attainment and relative factor costs. The model formulation is that of a finite state, finite action, Markov decision process. The results of this project can help maintenance engineers, building managers, and others responsible for making decisions concerning maintenance policies in selecting economically efficient levels of maintenance for elements of building service equipment. A report on the project, Equipment Maintenance for Energy Conseroation (NBSIR 77-1210, February 1977), describes the model and contains listings of computer programs to select an optimal policy. The report also contains an illustrative example applying the model to the maintenance of an air handling unit. 
